\title{
Recurrent meningitis and brain abscess caused by Eikenella corrodens
}

\author{
A. M. EMMERSON \\ B.Sc., M.B., M.R.C.Path. \\ F. Mills \\ M.B., M.R.C.P., D.T.M. \& H. \\ Departments of Medical Microbiology and Neurology, Whittington Hospital, London N19
}

\begin{abstract}
Summary
A case of recurrent meningitis and brain abscess caused by Eikenella corrodens in a patient with previous otitis media and mastoidectomy.
\end{abstract}

\section{Introduction}

Eikenella corrodens, a facultative anaerobic Gramnegative bacillus, was first characterized by Eiken in 1958 and is a rare cause of meningitis. It usually causes abscess formation with necrosis of the infected tissues. In 10-15\% of cases it causes infection in pure culture but more often is associated with cultures of both aerobic and strict anaerobic organisms.

The authors report a case of recurrent meningitis due to this organism and a non-haemolytic streptococcus in which $E$. corrodens was isolated repeatedly, not only from the cerebrospinal fluid (CSF) but also from a cerebellar abscess cavity.

\section{Case report}

A 60-year-old woman was first admitted with an 8-day history of insidious onset of fever, generalized headache, anorexia, vomiting after meals, poor concentration, bizarre and erratic behaviour and increasing drowsiness.

Thirty years before she had had a right faciohypoglossal nerve anastamosis performed for a right facial palsy without any benefit but with subsequent marked atrophy and fasciculation of the right half of the tongue. She had long-standing right perceptive deafness due to otitis media and mastoiditis for which a mastoidectomy had been performed 7 years previously.

Clinically she was alert but confused, had a temperature of $38.2^{\circ} \mathrm{C}$ and a tachycardia of $100 / \mathrm{min}$. No abnormalities were found in the cardiovascular, respiratory or gastrointestinal systems. She had signs of meningeal irritation with marked nuchal rigidity and a positive Kernig's sign. Her pupils and fundi were normal. Apart from her long standing right 7th and 12th cranial nerve palsies there was no motor or sensory loss and no evidence of cerebellar dysfunction. The reflexes were present and symmetrical with bilateral flexor plantar responses.

A clinical diagnosis of meningitis was made.
Investigations showed $\mathrm{Hb} 14.4 \mathrm{~g} / \mathrm{dl}$, WBC count $14.7 \times 10^{9} / 1\left(12.9 \times 10^{9} / 1\right.$ neutrophils, $1.47 \times 10^{9} / 1$ lymphocytes, $0.295 \times 10^{\circ} / 1$ monocytes) the ESR was $45 \mathrm{~mm}$ in the first hour (Westergren) and three blood cultures were taken and later proved sterile. A lumbar puncture revealed a turbid CSF with WBCs $6.3 \times 10^{9} / 1,\left(5.05 \times 10^{9} / 1\right.$ neutrophils $)$ protein 2.16 $\mathrm{g} / \mathrm{l}$ and glucose $0.31 \mathrm{mmol} / \mathrm{l}$. Culture of the CSF yielded a growth of an aerobic Gram-negative bacillus identified as $E$. corrodens (sensitive to ampicillin and chloramphenicol) and a non-haemolytic streptococcus (sensitive to penicillin, ampicillin, chloramphenicol and clindamycin). X-ray of the chest and skull appeared normal.

The patient responded satisfactorily to ampicillin $2 \mathrm{~g} / 4 \mathrm{hr}$ i.v. for 10 days followed by oral amoxycillin $1 \mathrm{~g} / 6 \mathrm{hr}$ and probenecid $500 \mathrm{mg}$ b.d. for 1 week. She became apyrexial and less confused within $48 \mathrm{hr}$ of the onset of therapy and was discharged well and asymptomatic on the 25th day of admission.

\section{Second admission}

The patient was re-admitted 10 days later with a relapse having been taken ill over the previous 24-48 hr with symptoms similar to her first admission. She was gravely ill, drowsy, confused and with a pyrexia of $37 \cdot 8^{\circ} \mathrm{C}$. There were signs of meningeal irritation but no new abnormal neurological findings. There was a peripheral leucocytosis of $24 \times 10^{\circ} / 1$ with an ESR of $69 \mathrm{~mm}$ in the first hour. A lumbar puncture yielded a purulent CSF with numerous Grampositive cocci later identified as a non-haemolytic streptococcus. E. corrodens was not isolated on that occasion. She responded to a similar regimen as instituted in her first illness but this was followed by chloramphenicol $250 \mathrm{mg} / 6 \mathrm{hr}$ orally for 2 further weeks. A repeat lumbar puncture performed on the 28th day of admission showed a crystal clear CSF with lymphocytes $0.046 \times 10^{9} / 1,1.5 \mathrm{~g} / 1$ protein but no organisms were cultured. She was discharged well on the 34th day of admission.

\section{Third admission}

The patient presented for the third time a month later with symptoms similar to her previous two admissions but in addition she complained of 
diplopia and inco-ordination of the right arm and leg. She was admitted 19 days later. Clinically, the main abnormal neurological findings were horizontal nystagmus more marked on lateral gaze to the right, marked cerebellar ataxia of the right arm and leg, ataxic gait and hyper-reflexia with bilateral flexor plantar responses. There were no signs of meningeal irritation this time. In view of the cerebellar signs a diagnosis of a right cerebellar abscess following meningitis was made.

A ventriculogram revealed a moderate degree of enlargement of both lateral ventricles but no displacement or deformity of the septum and the 3rd ventricle. The aqueduct and the 4th ventricle were displaced anteriorly and to the left indicating a spaceoccupying lesion in the right cerebellar hemisphere. A posterior fossa craniectomy revealed a right cerebellar abscess and $2 \mathrm{ml}$ of pus were aspirated, which yielded a moderate growth of $E$. corrodens. Further attempts at retapping of the abscess were unsuccessful. Following neurosurgery the patient was returned to the neurology wards and after many weeks finally died of pulmonary emboli and bronchopneumonia.

\section{Bacteriology}

On the first occasion that $E$. corrodens was isolated from the CSF it only appeared after $48 \mathrm{hr}$ incubation at $37^{\circ} \mathrm{C}$ and on media with $\mathrm{CO}_{2}$ enrichment. Growth occurred on blood agar (layered plates with Oxoid Columbia Agar base CM 331 and $10 \%$ horse blood) incubated anaerobically $(90 \%$ hydrogen and $10 \% \mathrm{CO}_{2}$ ) and on chocolate agar incubated in a candle jar. On the second episode of meningitis $E$. corrodens appeared after only $24 \mathrm{hr}$ incubation but still only with $\mathrm{CO}_{2}$ enhancement. Colonies were less than $0.5 \mathrm{~mm}$ in diameter and exhibited the characteristic pitting which on Gram-staining showed Gram-negative bacilli. The organism proved to be catalase-negative; oxidase positive; nitrate reduced to nitrite; arginine dihydrolase not produced; lysine and ornithine decarboxylase produced and acid not produced from carbohydrates. Factors $\mathrm{X}$ and $\mathrm{V}$ were not required for growth.

Sensitivity to antibiotics was determined by the Stokes (1968) disc diffusion method on Oxoid DST agar with added $7 \%$ lysed horse blood. The Oxford staphylococcus was used as a control organism. The $E$. corrodens isolates were judged to be sensitive to discs containing the antibiotics stated in the following amounts: ampicillin, $10 \mu \mathrm{g}$; chloramphenicol, $10 \mu \mathrm{g}$; tetracycline, $10 \mu \mathrm{g}$; and to be resistant to clindamycin, $2 \mu \mathrm{g}$; erythromycin, $5 \mu \mathrm{g}$; penicillin, 1 unit; metronidazole, $5 \mu \mathrm{g}$.

The non-haemolytic streptococcus isolated on three occasions grew readily both aerobically and anaerobically on blood agar overnight at $37^{\circ} \mathrm{C}$ but failed to group using Lancefield groups A, B, C, D and $G$ typing sera. The streptococcus was found to be sensitive to penicillin, ampicillin, chloramphenicol and clindamycin.

\section{Post-mortem findings}

The relevant pathology was confined to the central nervous system. Pus was found in the right cerebellar hemisphere which on culture yielded $E$. corrodens. The right petrous temporal bone in the anterior half showed bone destruction in the region demonstrated by X-ray ante mortem. Necrotic material removed from the petrous bone on culture yielded $E$. corrodens and a non-haemolytic streptococcus.

\section{Discussion}

Eiken (1958) characterized the organism which now bears his name but it was not until 1972 that Jackson and Goodman redefined the characteristics of the 'corroding bacilli' and reclassified the facultative organism as $E$. corrodens and separated the obligate anaerobes as Bacteroides corrodens. To date, few cases of cerebral abscess due to $E$. corrodens have been reported. In 1958 Eiken made a comprehensive study of some 21 strains, one of which was isolated from a cerebral abscess. Marsden and Hyde (1971) reported one case of $B$. corrodens (with an anaerobic streptococcus) isolated from an extradural abscess. Kaplan, McCracken and Nelson (1973) reported the isolation of $E$. corrodens from a brain abscess in conjunction with a microaerophilic streptococcus and Staphylococcus albus. Dorff, Jackson and Rytel (1974) recorded a case of meningitis due to $E$. corrodens alone.

The facultative Gram-negative bacillus is an inhabitant of the mouth and upper respiratory tract and many $E$. corrodens infections are associated with oral and gastrointestinal organisms. When $E$. corrodens causes meningitis, subdural empyema, osteomyelitis or endocarditis, it tends to be the sole infecting agent.

Recurrent meningitis may be due to congenital or traumatic anatomical skull defects, persistent parameningeal suppurative foci or impaired immunity. In this patient the suppurative focus was otogenic as is almost exclusively the case in cerebellar abscesses. Middle ear and mastoid infections are the predisposing factors in some $40 \%$ of brain abscess. This was confirmed in this case at post-mortem even though repeated ENT examination in life showed no evidence of active aural infection. There is ample evidence of significant predisposing factors shown in this case, and $E$. corrodens had ready access to the central nervous tissue to cause abscess formation with necrosis of infected tissues. Following the first 
episode of meningitis due to E. corrodens and a nonhaemolytic streptococcus, rapid clinical resolution followed vigorous parenteral ampicillin and subsequent oral amoxycillin. This episode was quickly followed by a second attack of meningitis due this time to the non-haemolytic streptococcus alone. This illness reponded to a similar regimen and following this a suppressive dose of chloramphenicol was given in an endeavour to prevent further relapse. This was in vain, as a further episode revealed a brain abscess which subsequently yielded $E$. corrodens yet again. In spite of surgery and prolonged therapy both $E$. corrodens and the non-haemolytic streptococcus were isolated from brain tissue at post-mortem some 8 months later.

In an extensive review by Brooks et al. (1974) these workers reported that $E$. corrodens is resistant to clindamycin and metronidazole-unlike $B$. corrodens - and Eikenella spp. infections are relatively resistant to aminoglycoside antibiotics and are not indicated for treatment.

\section{Acknowledgment}

We thank Dr Croft, Consultant Neurologist at the Whittington Hospital for permission to publish this case and to express our thanks to Dr L. R. Hill of the National Collection of Type Cultures for confirming the identification of the Eikenella sp. We are grateful to Dr Pauline A. Kahn, the Consultant Neuropathologist at the Whittington Hospital for the post-mortem report.

\section{References}

Brooks, G.F., O'Donoghue, J.M., Rissing, J.P., Soapes, K. \& SMITH, J.W. (1974) Eikenella corrodens, a recently recognized pathogen. Medicine, 53, 325.

DoRfF, G.J., JACKSON, L.J. \& RYTEL, M.W. (1974) Infections with Eikenella corrodens a newly recognized human pathogen. Annals of Internal Medicine, 80. 305.

EIKEN, M. (1958) Studies on an anaerobic rod-shaped, Gramnegative microorganism: Bacteroides corrodens n.sp. Acta pathologica et microbiologica scandinavica, 43, 404.

JACKson, F.L. \& Goodman, Y.V. (1972) Transfer of the facultatively anaerobic organism Bacteroides corrodens Eiken to a new genus Eikenella. International Journal of Systematic Bacteriology, 22, 73.

Kaplan, J.M., McCracken, G.H. \& Nelson, J.D. (1973) Infections in children caused by the $\mathrm{HB}$ group of bacteria. Pediatrics, 82, 398.

MARSDEN, H.B. \& HYDE, W.A. (1971) Isolation of Bacteroides corrodens from infections in children. Journal of Clinical Pathology, 24, 117.

Stokes, E.J. (1968) Clinical Bacteriology, 3rd edn, p. 179. Arnold, London. 